\title{
0 modernismo no estilo musical tardio de Gabriel Fauré: aspectos estilísticos e formais do Primeiro Movimento do Deuxième Quintette pour Piano et Cordes Op.115
}

\author{
Nahim Marun (UNESP, São Paulo, SP) \\ nmarun@uol.com.br
}

\begin{abstract}
Resumo. Análise dos aspectos estilísticos da última fase composicional de Gabriel Fauré, focando sobre aspectos harmônicos, contrapontísticos, rítmicos e formais encontrados no Primeiro Movimento do Deuxième Quintette pour Piano et Cordes Op. 115.

Palavras-chave: Gabriel Fauré, análise musical, estilo musical, música de câmara, interpretação musical.
\end{abstract}

The modernism in the late Gabriel Fauré's musical language: stylistic and formal features of the First Movement of the Deuxième Quintette pour Piano et Cordes Op.115

Abstract. Analysis of Gabriel Fauré's late musical style, with focus on the harmony, counterpoint, rhythm and formal structure of the First Movement of the Deuxième Quintette pour Piano et Cordes Op. 115.

Keywords: Gabriel Fauré, musical analysis, musical style, chamber music, musical performance

\begin{abstract}
1. Introdução
Gabriel Fauré (1845-1924) vivenciou uma época de grandes mudanças no pensamento musical ocidental. Ao longo dos anos, o compositor absorveu essas transformações e construiu lentamente um estilo musical original, complexo e refinado. Sua música transborda uma grande "sinceridade artística". Esse conceito, renegado por sua aparente ausência de valor científico, surgiu resgatado por CABALLERO (2001, p.11-57), no livro Fauré and French Musical Aesthetics. No primeiro capítulo dessa obra, intitulado The Question of Sincerity, demonstra-se a importância capital desse parâmetro de valor para Fauré e para toda uma geração de artistas franceses do início do século XX. 0 autor cita as próprias palavras Fauré: "Há certas obras que não necessitam ser catalogadas como arcaicas ou modernas, porque elas são belas e sinceras." (CABALLERO, 2001, p.16). Charles Koechlin (1867-1950) assim se referiu a seu mestre: suas sonatas "me iluminaram com luz serena e absoluta sinceridade". (CABALLERO, 2001, p.18).
\end{abstract}

Neste artigo veremos uma análise de vários elementos importantes da linguagem musical tardia de Fauré e ressaltaremos a importância capital do seu estilo para a produção estético musical do século XX.

\section{0 amadurecimento artístico e os dois}

\section{Quintetos para piano e cordas}

Segundo ORLEDGE (1979, prefácio), podemos dividir a vida e obra de Gabriel Fauré em três fases criativas. 0 primeiro período de 1860 a 1885; o segundo período de 1885 a 1906 e o último período de 1906 a 1924. Freqüentemente mencionado como um dos principais representantes do movimento romântico francês, o compositor é bastante reconhecido pelos trabalhos de sua primeira fase "romântica", que figuram com relativa freqüência nos programas de concertos dentro e fora da França. Como exemplo desse primeiro período, podemos citar a Ballade Op. 19 (1881), composta originalmente para piano solo e orquestrada mais tarde por sugestão de Franz Liszt (1811-1886), a Premier Sonate pour Piano e Violon Op. 13 (1875), o Premier Quartour avec Piano Op. 15 (1876-9), algumas canções como Après un Rêve Op. 7 no. 2 (1878), Automne Op. 18 no. 3 (1878), Notre Amour Op. 23 no. 2 (1879) e os primeiros opus das treze Barcarolas e dos treze Noturnos para piano solo.

No entanto, são nos trabalhos da segunda e terceira fases composicionais que sua linguagem adquire uma força artística sem precedentes. Segundo COPLAND (1924/1991, 
p.49), o longo período de amadurecimento, necessário para depurar a linguagem de Fauré, injustamente tornou-se um fator para lançar sua obra a um relativo esquecimento. Talvez o público e a crítica parisienses dessa época estivessem grandemente seduzidos pelo entretenimento dos années folles, ou pela avalanche de experimentação ousada trazidos pelos jovens compositores e pelas influências das culturas extra-européias. A discreta modernidade da linguagem de Fauré do último período não lhe trouxe o merecido reconhecimento. No mencionado artigo, publicado exatamente no ano da morte de Fauré, o jovem Aaron Copland nos chama a atenção para as grandes inovações presentes no trabalho tardio de Gabriel Fauré. Copland considerou Fauré como o "Brahms da França", explicando que "não significa absolutamente que (Fauré) imite Brahms, pois ele possui um gênio, um estilo particular e uma técnica tão perfeita quanto o mestre alemão."

É muito interessante buscar alguns dos fundamentos que originaram essa constatação e analisar a ambigüidade musical presente na obra de ambos os compositores Brahms e Fauré - considerando-se suas muitas intersecções estéticas. Em artigo da Current Musicology, ARNONE (2006) discute a música de Brahms e a ambigüidade inerente aos elementos de sua música. Podemos concluir que vários pontos de vista defendidos pelo autor poderiam ser igualmente aplicados à música de Fauré, como por exemplo, a pouca diferenciação de texturas entre a melodia-acompanhamento e a relativização de parâmetros formais, métricos e harmônicos. Para citar algumas passagens específicas, vejamos as típicas hemíolas tão exploradas por Brahms, que aparecem insistentemente no quarto movimento do Deuxième Quintette pour Piano et Cordes Op. 115 e o tratamento da harmonia em ambos os autores que evitam sistematicamente as posições fundamentais dos acordes. No caso específico de Fauré, a fusão da tonalidade com os modos eclesiásticos confere uma originalidade particular ao seu sistema harmônico. Ainda podemos constatar em ambos os compositores, muitos exemplos de texturas musicais que fundem admiravelmente bem as tramas da melodia e do acompanhamento.

Segundo CABALLERO (2001, p.26), Émile Vuillermoz, que fora um dos alunos ilustres de Fauré, escreveu crítica sobre o Deuxième Quintette pour Piano et Cordes Op. 115 em 1921 e endereçou, em suas entrelinhas, uma crítica severa ao "grupo dos seis". Assim se expressou Vuillermoz: "Nos seus quatro movimentos há mais incorporações de modernidade do que em todas as bandeiras agitadas por certos aprendizes em música, ansiosos em estabelecer uma revolução em benefício próprio".

Segundo COOPER (1951, p.141), a partir de 1907, as obras de Fauré praticamente renunciam à cor, e até mesmo a escrita ornamental pianística, típica de sua primeira fase, foi progressivamente modificada. Ainda segundo COOPER (1951, p.152), "o conteúdo intelectual tornou-se denso, as harmonias cada vez mais elípticas, as linhas melódicas cada vez mais severas, econômicas e construídas com menos notas." Fauré foi um dos primeiros compositores a liderar um movimento para a remoção do "não essencial" da música, que se tornou uma tendência importante para a vanguarda musical do pós-guerra 1914-18.

No domínio dos quintetos de corda com piano, Fauré contribuiu com duas obras primas para o gênero: 0 Premier Quintette pour Piano et Cordes Op. 89 em Ré menor (1906) e o Deuxième Quintette pour Piano et Cordes Op. 115 em Dó menor (1921). Segundo SMALLMAN (1996, p.113), tais obras demonstram uma pureza clássica de estilo e um notável equilibrio. Fauré expande sua técnica musical, impregnando esses quintetos de uma nova intensidade, constantemente emocional, porém carregados de moderação e contenção. Segundo ORLEDGE (1979, p.314), Eugène Ysaÿe (1858-1931), com o seu quarteto e o próprio Fauré como pianista, deram a primeira audição do Premier Quintette pour Piano et Cordes Op. 89 no Cercle Artistique de Bruxelas, no dia 23 de Março de 1906. Segundo SMALLMAN (1996, p.114), o grande violinista assim descreveu a natureza essencial do pensamento do compositor nessa obra: "total rejeição do exibicionismo" e uma habilidade para criar uma "música absoluta, no mais puro sentido da sua expressão". Conforme o catálogo de ORLEDGE (1979, p.323), o Deuxième Quintette pour Piano et Cordes Op. 115 foi estreado na Société Nationale de Paris em 21 de Maio de 1921, com Robert Lortat (piano), André Toumet e Victor Gentil (violinos), Maurice Vieux (viola) e Gérard Hekking (violoncelo).

\section{Algumas particularidades da harmonia empregada por Gabriel Fauré:}

Segundo GERVAIS (1971, p.272-3) comparando-se a linguagem harmônica de Debussy e Fauré observamos que ao contrário de Debussy, "Fauré reuniu modalidade e tonalidade numa fusão tão intima que elas formam uma única e perfeita linguagem harmônica".

Sabe-se que na época de Fauré, o uso dos modos já não era uma inovação dentro do sistema tonal. Podemos assinalá-los já em Beethoven (Heiliger Dankgesange), em César Frank (Prélude, Choral et Fugue) e em diversas obras de Chopin (a exemplos das Mazurcas, Concertos e Baladas), para citar somente alguns exemplos. Porém, na maioria dos casos, os modos gregorianos eram incorporados em momentos específicos para obtenção de um efeito característico. Na música de Fauré, no entanto, ocorre uma total integração destes modos ao sistema tonal, revigorando e transformando a percepção da própria tonalidade. Segundo LONG (1981, p.21), a habilidade em trabalhar com estes modos teve origem nos dez anos de estudos rigorosos que o compositor realizou na tradicional École Niedermeyer de Paris, conhecida por preparar alunos para o ofício de mestres cantores e organistas.

A técnica composicional de Fauré utiliza-se de escalas tonais e modais sem levar em consideração suas diferenças e polaridades. 0 compositor criou uma linguagem que funde escalas semelhantes, ou seja, considera aparentadas as escalas com polaridades comuns. Muitas 
vezes o compositor combina até mesmo dois tetracordes distintos, um de cada modo musical, criando assim uma nova escala musical. Outras vezes, Fauré enfraquece o efeito da nota sensivel, abaixando-a em meio tom. Segundo JOHANSSON (1999, p.63), "paradoxalmente, o elemento que parece constituir obstáculo principal para uma melhor apreciação das obras tardias de Fauré - o estilo harmônico singular e muito complexo - constituem também sua qualidade mais encantadora." Ainda segundo esse autor, "a linguagem harmônica de Fauré parece resumir e sintetizar todos os recursos e todas as possibilidades do sistema harmônico tonal, e ao mesmo tempo incorpora os elementos mais antigos da música modal." $A$ cadência plagal, justamente por sua característica modal e ausência da nota sensível, tornou-se um dos meios de articulação e de conclusão musicais favoritos de Gabriel Fauré. Podemos observá-las na articulação de fraseado nos compassos 9, 21 e 182 do Deuxième Quintette pour Piano et Cordes Op. 115. No exemplo a seguir, em poucos compassos extraídos desse quinteto, podemos constatar três procedimentos típicos da linguagem de Fauré: a nota
Lá bequadro - no compasso 181 - insinua uma modulação para o modo lídio, se relacionarmos a frase anterior à tonalidade de Mi bemol maior que é confirmada logo a seguir; ou indica uma passagem pelo modo dórico se relacionarmos a frase à tonalidade de Dó menor, tônica da obra. Uma típica cadência plagal aparece no compasso 182-183. Podemos observar também o emprego da enarmonia da nota Mi bemol - Ré sustenido, que imediatamente conduz a tonalidade para outra região.

Fauré usou com muita parcimônia a escala de tons inteiros, normalmente aplicando-a em passagens curtas ou então integradas ao contexto tonal-modal. Podemos observá-la no exemplo seguinte, na linha melódica. Tal escala aparece harmonizada com acordes de configurações semeIhantes aos acordes clássicos de Jean Philippe Rameau (1683-1764), ou seja, os arquetípicos acordes de quinta e sexta acrescentada. Percebemos mais uma vez, a criação de um sistema musical híbrido e elástico que funde magistralmente os princípios da tonalidade clássica a elementos musicais novos, nesse caso, a escala de tons inteiros.
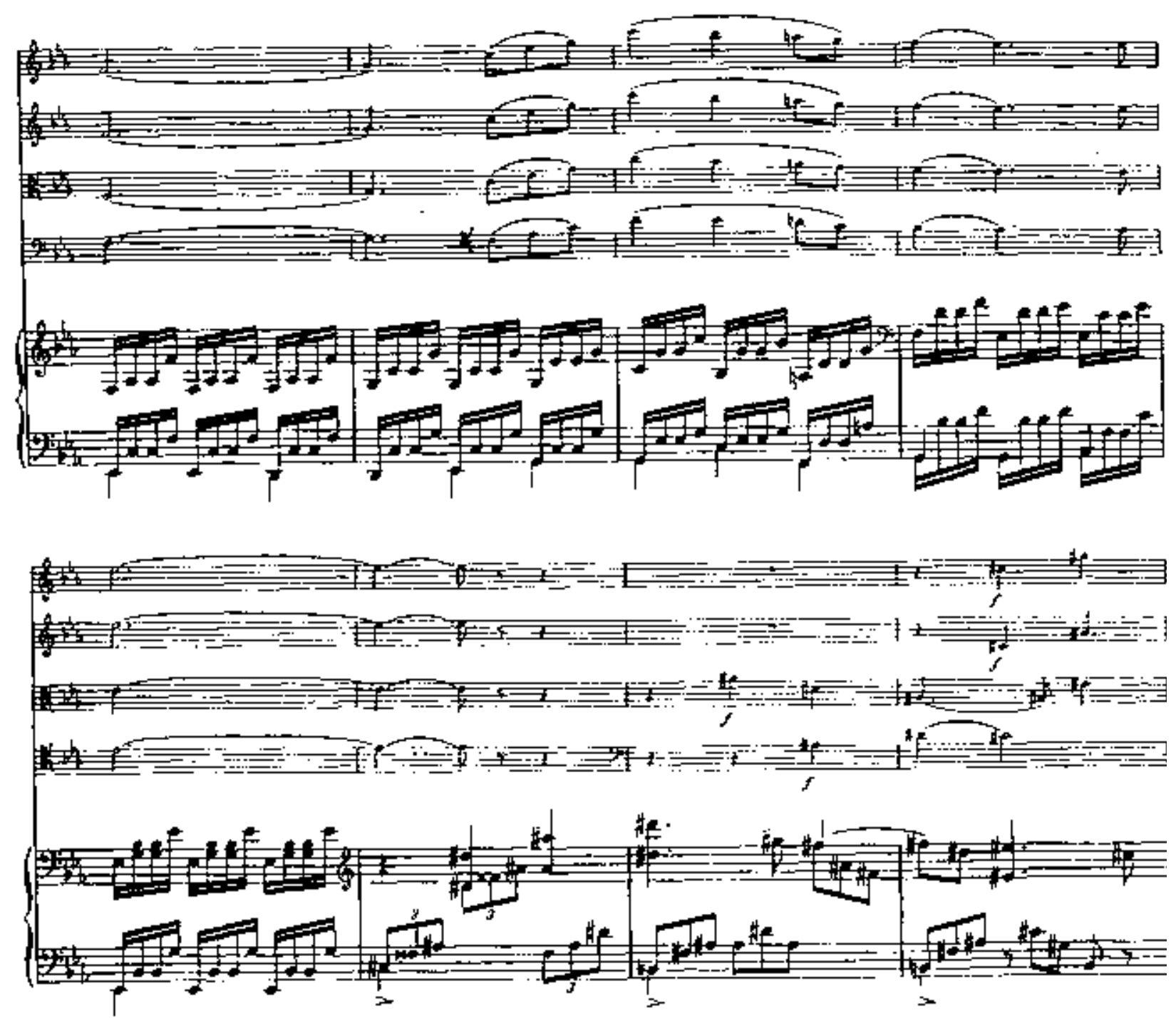

Ex. 1: Gabriel Fauré. Deuxième Quintette pour Piano et Cordes Op. 115, 1. Mov, c.179-186. 


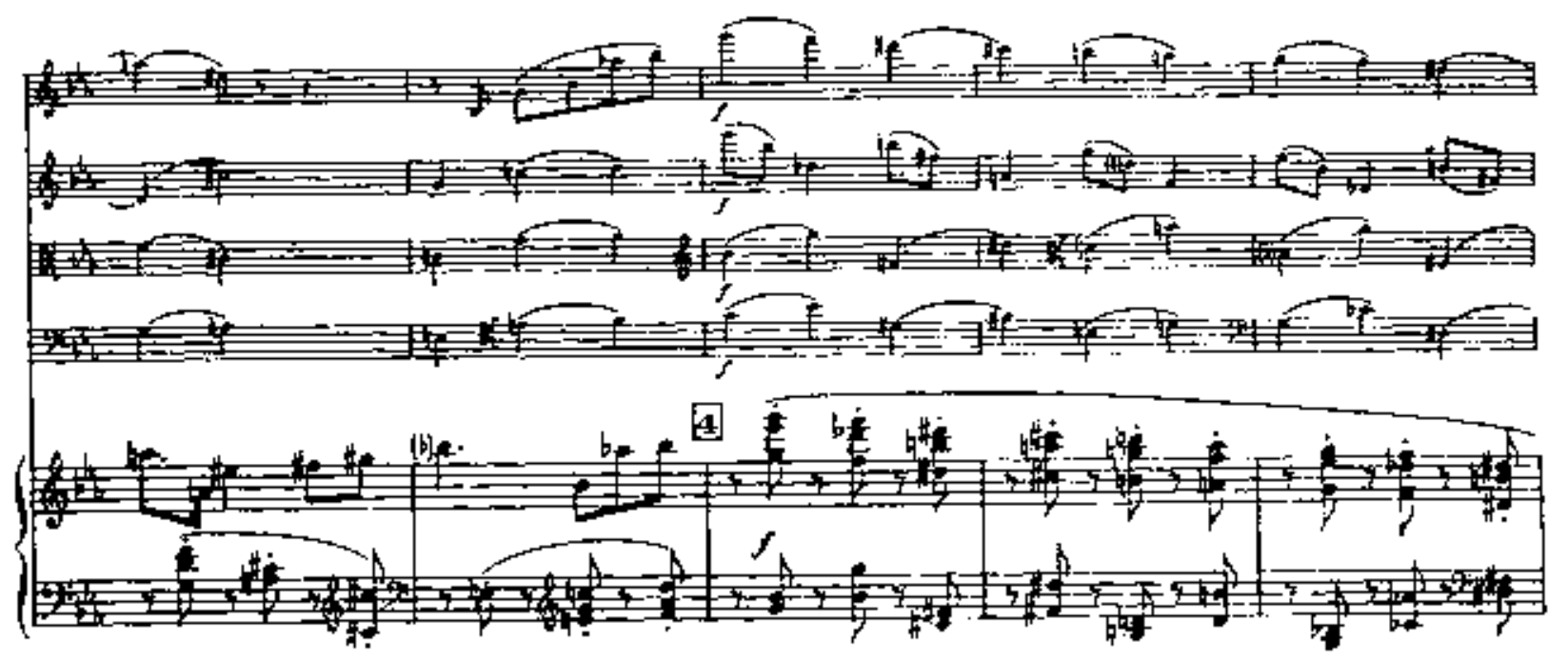

Ex. 2: Gabriel Fauré. Deuxième Quintette pour Piano et Cordes Op. 115, 1‥ Mov, c. 73-77. Escalas de tons inteiros na linha melódica harmonizadas tonalmente

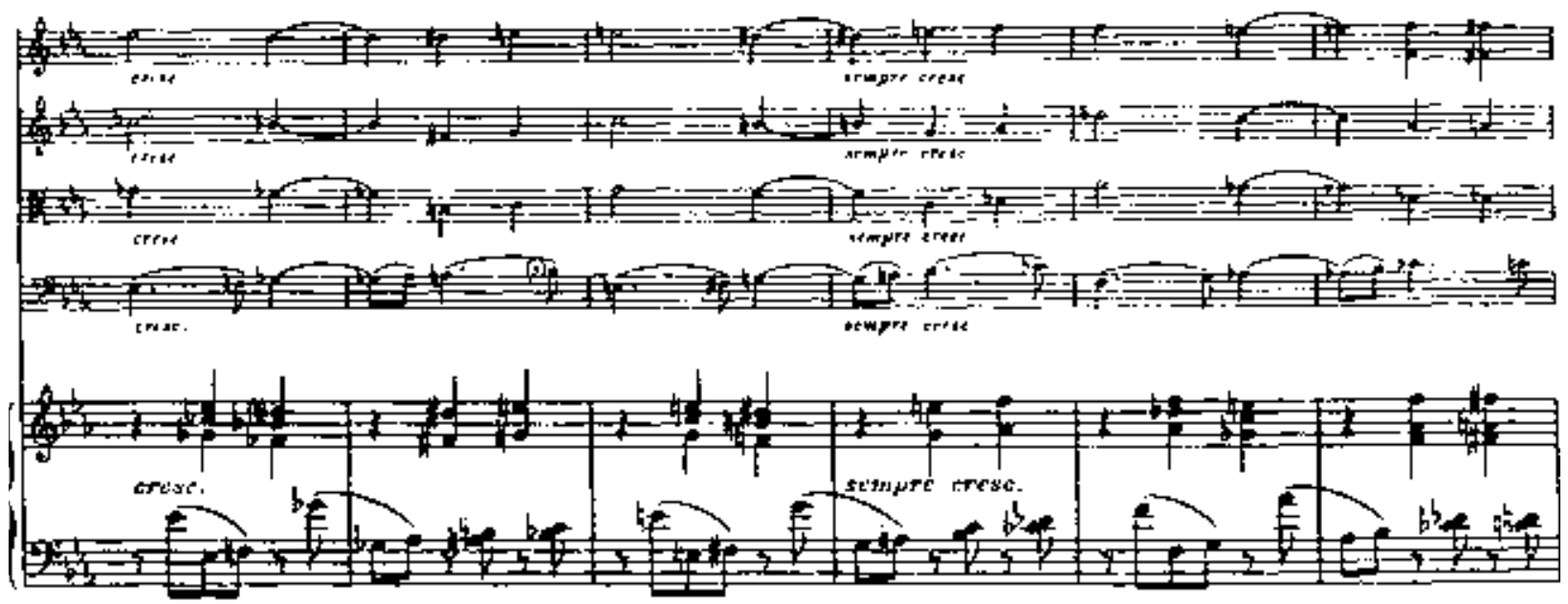

Ex. 3: Gabriel Fauré. Deuxième Quintette pour Piano et Cordes Op. 115, 1. Mov, c. 171-176. Uso de cromatismo em cadeia e de acordes alterados

A profunda integração desses sistemas de composição e escalas diversas provoca no ouvinte uma sensação auditiva inovadora de dilatação do sistema tonal. JOHANSSON (1999, p.63-64) defende a idéia que a linguagem de Fauré "escapa a todos os métodos convencionais de análise harmônica. A análise tradicional em algarismos romanos, mesmo quando alargada incluindo acordes alterados ou cromáticos, é claramente insuficiente". A "análise schenkeriana indica com clareza a longa direção tonal, mas parece ser incapaz de explicar as origens de certas complexidades harmônicas presentes no primeiro plano." A principal falha de muitos dos métodos analíticos é a exigência de decisões categóricas, excluindo as interpretações alternativas, e impondo às situações equívocas uma só possibilidade de resolução.
A harmonia de Fauré floresceu dentro do equívoco e não se explica completamente ou corretamente partindo-se de um só ponto de vista analítico. JOHANSSON (1999, p.69) assinala que o equivoco harmônico em Fauré não se configura simplesmente pelo uso de acordes individuais que se resolvem de maneira inesperada, mas sim pelo emprego sistemático de um equívoco sustentado que resulta em uma série de enganos individuais, provocando uma seqüência de ambigüidades sucessivas que envolvem a tonalidade e sua direção em um complexo caleidoscópio tonal.

Segundo ORLEDGE (1979, p.246), Fauré explora a ambigüidade e a flutuação harmônica através do uso de acordes alterados, ou seja, acordes diminutos ou aumentados que muitas vezes se encadeiam dando a impressão 
de "modulações" auditivas que de fato não ocorrem. As alterações são empregadas em todos os graus da escala, com uma predileção pelos III e VI graus. JOHANSSON (1999, p.78) nos confirma essa informação, assegurando que muitos dos encadeamentos harmônicos audaciosos de Fauré não se confirmam em modulações definitivas, mas apresentam-se somente como sugestões fugazes desse procedimento tonal. Freqüentemente "existe a sensação de estarmos muito longe do nosso ponto de partida, porém na verdade, estamos somente a um passo da resolução".

\section{Considerações sobre o contraponto e rit- mo:}

Segundo ORLEDGE (1979, p.255-258), no segundo e terceiro períodos, o compositor criou uma técnica inovadora onde ocorre uma interpenetração entre o ritmo melódico e o ritmo harmônico. Geralmente a tensão da harmonia aumenta enquanto a tensão melódica decresce ou viceversa, criando uma alternância paradoxal entre equilibrio e conflito. Segundo MELLERS (1947, p.61-2), "Fauré criou um idioma de potência quase bachiana por meio de grande vigor na linha melódica e de um domínio rigoroso sobre o baixo. A melodia e o baixo são interdependentes" (exemplo 4).

Segundo VUILLERMOZ (1983, p.136), "a linha melódica de Fauré caracteriza-se geralmente por frases longas e expansivas com intervalos largos". Por outro lado, segundo JOHANSSON (1999, p.78), pequenos movimentos contrapontísticos, geralmente de um tom ou de um semitom no interior da trama harmônica são igualmente muito importantes na música de Fauré. Muitas vezes, a re-escritura enarmônica de uma nota a insere dentro de um novo contexto e lhe confere um novo significado.

Nas suas últimas obras, Fauré procurou não evidenciar a métrica e os acentos convencionais dos tempos fortes. Para obtenção desse efeito, o compositor utilizou ritmos pouco marcados e explorou uma intrincada escrita contrapontís- tica. Fauré se influenciou muito pouco pela poderosa rítmica da primeira fase de Igor Stravinsky (1882-1971) ou Béla Bartók (1910-1949). Entre as poucas exceções, podemos citar a Fantaisie Op. 111 pour Piano et Orchestre.

No Deuxième Quintette pour Piano et Cordes Op. 115, nota-se o uso sistemático de ligaduras aplicadas do tempo fraco ao forte, evitando desta maneira o apoio regular do primeiro tempo. Segundo FORTASSIER (1976, p.5), há uma tendência em Fauré em evitar o ritmo iambo que, segundo MEYER e COOPER (1960, p.6), é um dos cinco agrupamentos rítmicos, tradicionalmente associados com a prosódia. Segundo FORTASSIER (1976, p.5), o uso restrito do ritmo iambo fraco/forte pelo compositor reflete uma tendência típica da língua francesa, fato evidenciado na estruturação rítmica das suas mélodies para canto e piano.

Pode-se notar até mesmo uma tendência no compositor em abolir a barra de compasso; porém ele nunca a abandonou de fato, como fizeram alguns de seus contemporâneos. Segundo ORLEDGE (1979, p.259), Fauré freqüentemente construía frases com cruzamento de vozes e sentenças musicais de métrica irregular, criando desse modo, um novo artifício para não evidenciar a métrica.

\section{Considerações sobre a estruturação musical:}

Fauré desenvolveu e expandiu sua herança musical, assimilando e transformando os gêneros musicais e estabelecendo um constante diálogo com o passado. 0 compositor influenciou-se por J. S. Bach (1685-1750) nas duas fugas que fazem parte das Huit Pièces Breves Op. 84. Segundo TODD (1990, p.198), o compositor inspirou-se em Felix Mendelssohn (1809-1847) nos Trois Romances sans Paroles Op. 17 e ainda segundo GILLESPIE (1972, p.305), em Robert Schumann (1810-1953) no Thème et Variations Op. 73 - comparar com os Estudos Sinfônicos Op. 13 - em Frédéric Chopin (1810-1849) nos Impromptus, Nocturnes e Barcarolles e em Franz Liszt (1811-1886), ao inspirar-se na Sonate en Si menor para compor a forma cíclica da Ballade Op. 19.

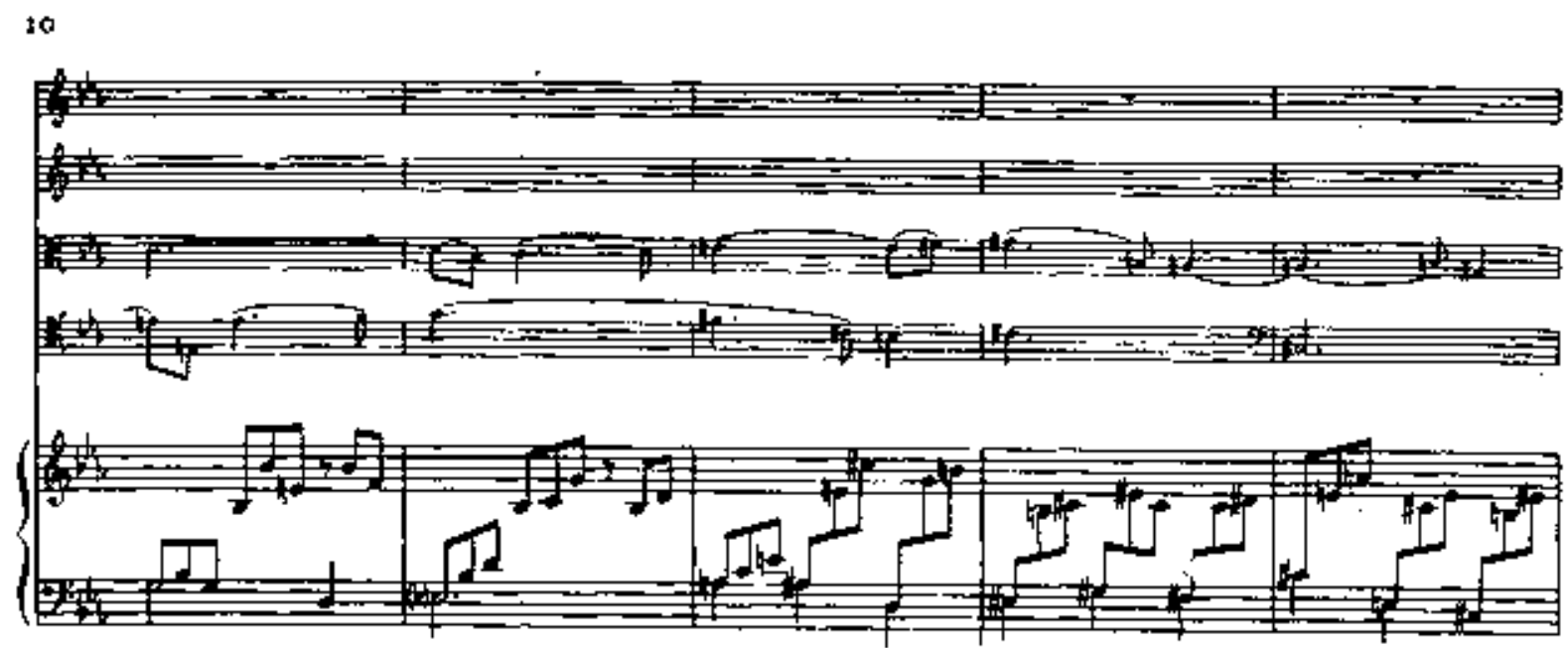

Ex. 4: Gabriel Fauré. Deuxième Quintette pour Piano et Cordes Op. 115, 1. Mov, c. 119-123. Intrincado contraponto 

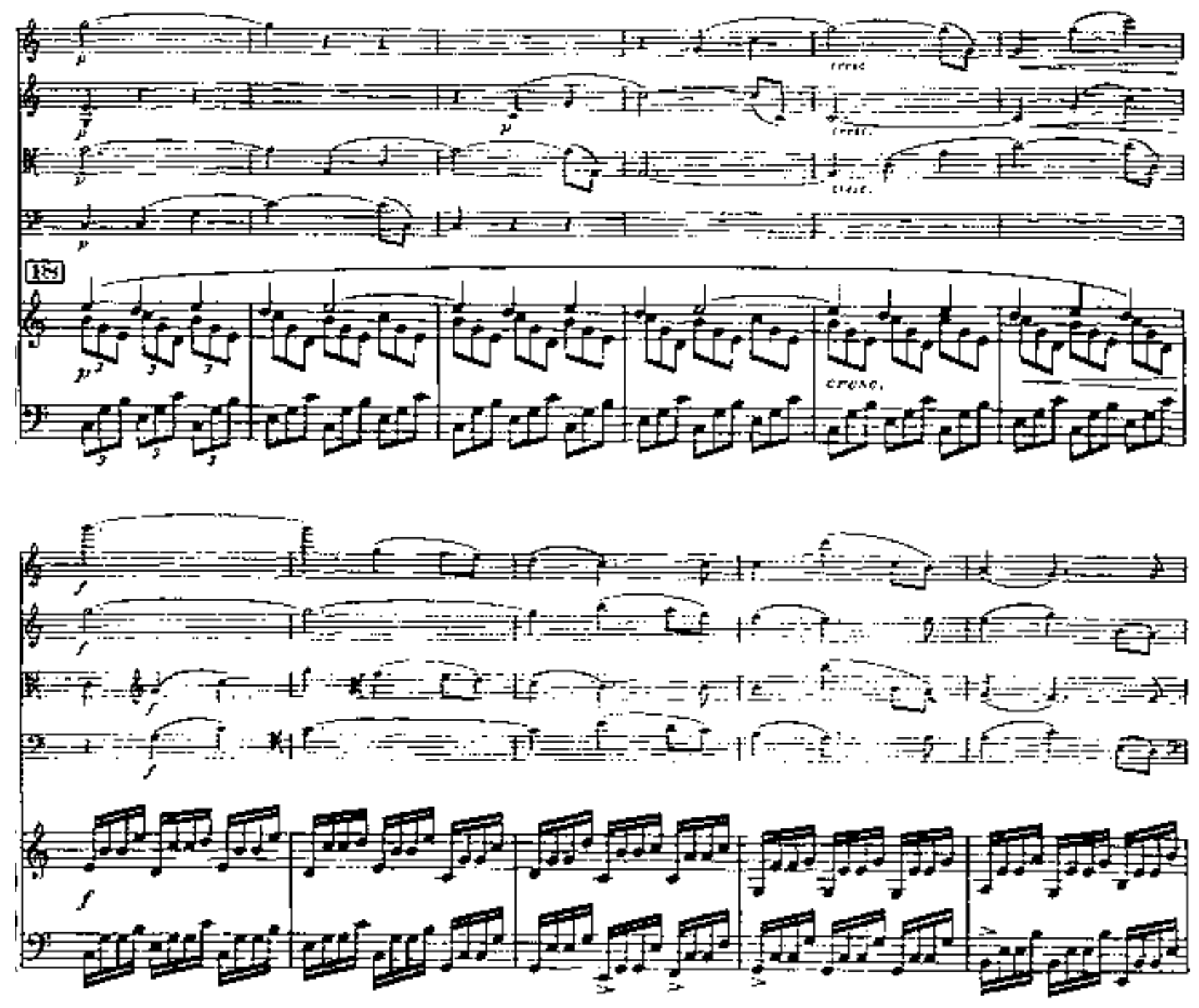

Ex. 5: Gabriel Fauré. Deuxième Quintette pour Piano et Cordes Op. 115, 1. Mov, c.265-276. Coda: contraponto com linhas melódicas de tessitura ampla
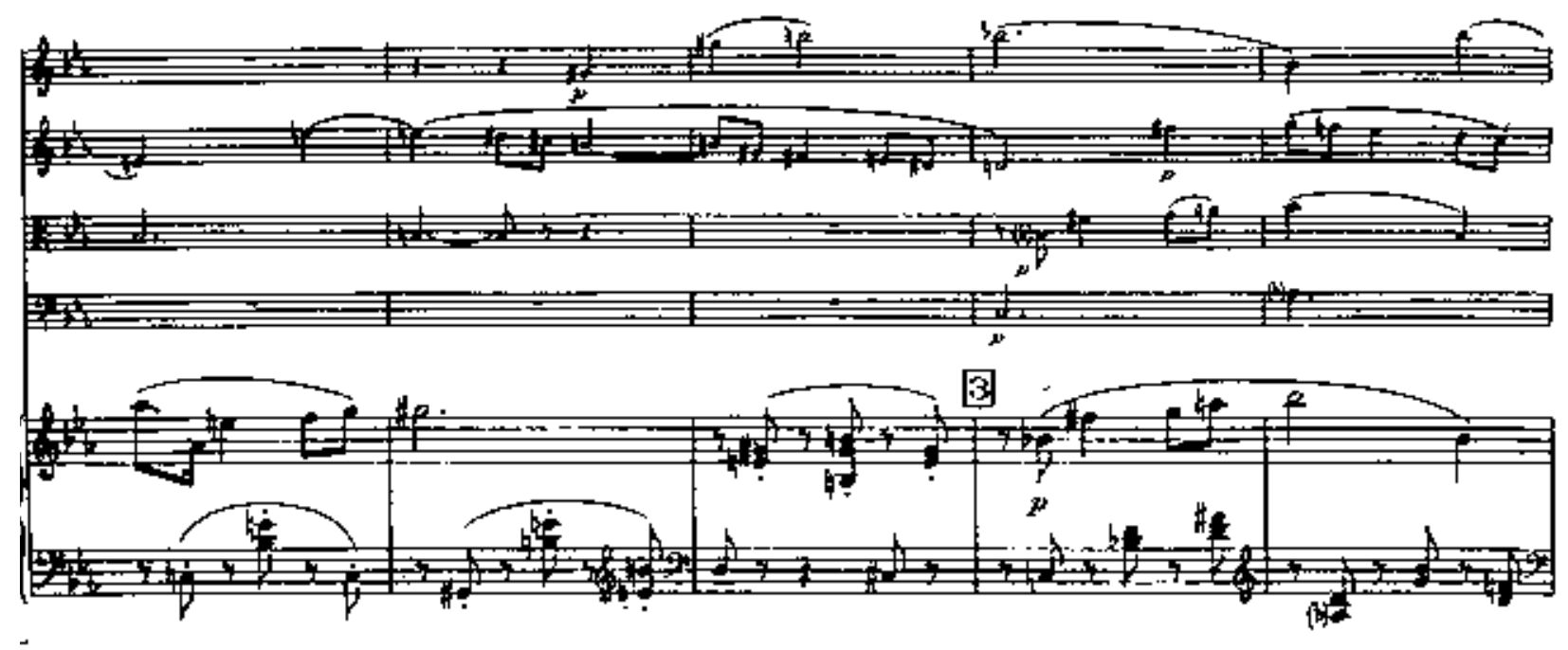
$\underline{-}$

Ex. 6: Gabriel Fauré. Deuxième Quintette pour Piano et Cordes Op. 115, 1. Mov, c. 52-56. Intenso contraponto e baixos em contratempos que minimizam os apoios em tempos fortes e emprestam leveza ao discurso 


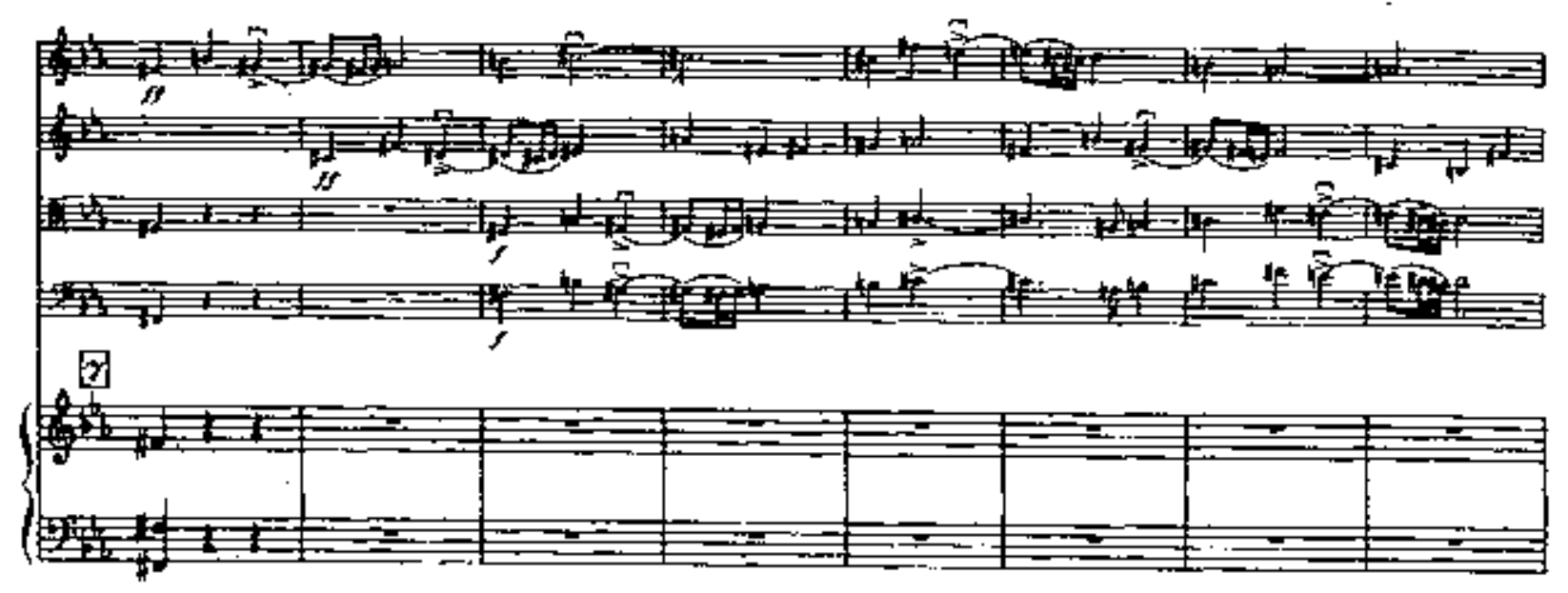

Ex. 7: Gabriel Fauré. Deuxième Quintette pour Piano et Cordes Op. 115, 1. Mov, c. 124-131. Fugato

Segundo ORENSTEIN (1991, p.123), Fauré adotou uma simetria tonal clássica ao estabelecer as relações entre os movimentos internos da maioria das suas obras de câmara. No Deuxième Quintette pour Piano et Cordes Op. 115, o Primeiro Movimento está em Dó menor/ maior, o Segundo Movimento em Mi bemol maior, o Terceiro Movimento em Sol maior e o Quarto Movimento novamente em Dó menor/maior.

Em seguida, veremos em maiores detalhes uma proposta de análise do autor deste artigo, que demonstra como 0 Primeiro Movimento do Deuxième Quintette pour Piano et Cordes Op. 115 se relaciona com as formas Pré-Clássicas de composição. Seu desenvolvimento ininterrupto emprega vários recursos polifônicos, como os fugatos (exemplo 7) - e uma escrita pianística que remete ao Baixo Contínuo do período Barroco.

\subsection{Análise formal do Primeiro Movimento do Deuxième Quintette pour Piano et Cor- des Opus 115.}

Segundo SMALLMAN (1996, p.119) o Primeiro Movimento dessa obra adota um "processo de desenvolvimento contínuo, no qual o tema principal (compassos 83, 177 e 267), anuncia o início de novas seções e possui função estabilizadora, e não de recapitulação". Em crítica para a revista Musical Times, HOPKINS (1974, p.44) observou que nos quintetos com piano, Fauré renunciou aos contrastes dinâmicos da Forma Sonata. 0 Primeiro Movimento do Deuxième Quintette pour Piano et Cordes Op. 115 é construído como um "fundo constante de fluxo contínuo" que valoriza essencialmente a equanimidade entre o primeiro e segundo temas e entre o piano e as cordas.

Nós poderiamos ir adiante destas constatações e acrescentar que Fauré desenvolve esse movimento aplicando vários procedimentos típicos das formas musicais Clássicas e Pré-Clássicas, aproximando-se do Concerto Grosso e das Árias em Ritornello do período Barroco. Segundo MICHELS (1985, p.123), uma das instrumentações típicas do Concerto Grosso se desenvolveu utilizando como formação dois violinos, violoncelo e contínuo. Nesse gênero, o Tutti (ou ripieno) expõe o tema na tonalidade da tônica, ou próxima dela, e os solistas tocam os episódios em tonalidades mais afastadas ou mesmo modulantes, explorando motivos temáticos livres.

Existe também um parentesco tonal com a Forma Sonata no plano geral das tonalidades, como por exemplo, as relações do Tema $C$ que apesar da instabilidade modulante, aparece inicialmente polarizando Si bemol que é uma tonalidade relacionada à dominante menor. Na ultima exposição, o mesmo tema aparece polarizando Mi bemol, que é uma tonalidade relacionada à tônica.

Os temas com função estabilizadora citados por Smallman são o Tema $A$ e suas pequenas variantes, que aparecem em tonalidades próximas do centro tonal Dó menor. Vejamos, a seção iniciada no compasso 83 está em Sol menor, a iniciada no compasso 177 em Mi bemol Maior. Portanto, podemos inferir que a sensação musical de solidez deriva principalmente de pilares de tonalidades construídas sobre as notas fundamentais Dó, Mi bemol e Sol, que por sua vez compõem a tríade do tom principal do quinteto: Dó menor. 


\subsection{Seções estruturais}

c. 1-34 Primeiro pilar tonal: Exposição Tema A

Apresentação temática da viola, seguida pelos solos do violoncelo, do segundo e primeiro violinos. 0 tema principal é derivado da célula de acompanhamento contínuo apresentado pelo piano, o que configura uma técnica de desenvolvimento temática típica do Classicismo musical.

c. 35-44:

Tema $B$

Tema breve, de influência eminentemente bachiana. Nesse momento esse material musical é exposto exclusivamente pelas cordas.

c. 45-78:

Tema C

Desenvolvido pelo piano. 0 material melódico é derivado do Tema A. A técnica de derivar temas de um original, aplicando-os em diferentes momentos da estrutura musical é característica do Estilo Clássico.

Essa é a primeira região de desenvolvimento modulante, onde os solistas se alternam em constante diálogo. 0 contraste de caráter entre os Temas $A$ e $C$ (típicos da Forma Sonata) acontece por suas diferenças de densidade e de estabilidade harmônica.

c. 79-82:

Tema utilizado para articular a forma. Caráter de passagem, estático.

\section{c. 83-107:}

Segundo pilar tonal: Segunda exposição do Tema $A$.

Apresentação temática do primeiro violino com a viola, seguidos imediatamente pelo segundo violino e violoncelo. 0 tema é desenvolvido em pares pelas cordas e intensificado pela expressividade, dos contrastes e das modulações.

\section{c. 108-124:}

Terceira exposição do Tema $A$

0 material temático é apresentado novamente com nova textura mais leve e pela primeira vez, desenvolvido pelo piano em diálogo com as cordas.

\section{c. $125-134$ :}

Tema $B$

Material musical bachiano apresentado no compasso 35 e exposto ainda exclusivamente pelas cordas, em fugato.

c. 135-160:

Tema C

Textura musical ainda mais fluida e transparente que na seção da exposição. À maneira dos episódios que compõe o Concerto Grosso do período Barroco, os solistas se alternam em uma segunda região de desenvolvimento modulante.

\section{c. 161-176:}

Articulação formal. Desenvolvimento cromático do material de 79-82.

\section{c. 177-185:}

Terceiro pilar tonal:

Quarta exposição do Tema A

Nessa exposição o material temático aparece, pela primeira vez, em uníssono tocado por todas as cordas e acompanhado pelo contínuo do piano. Fauré explora uma intensidade crescente no material temático.

\section{c. 186-192:}

Tema A

Há uma evidência cada vez maior da fusão dos três elementos temáticos do movimento:

Tema A / Tema B / Tema C

Iniciando a terceira região de desenvolvimento modulante, observar os fragmentos ou antecipações do Tema $B$ no violoncelo.

\section{c. 194-210:}

Tema $B$ aparece, pela primeira vez, acompanhado pelo piano, ocorrência que reforça a reconciliação instrumental e temática dos elementos musicais e aumenta a intensidade expressiva e emocional.

\section{c. 210-249:}

Tema C

Material do Tema C com interferências do Tema $B$.

A tonalidade apresentada pelo Tema $C$ na re-exposição prepara o advento de Dó Maior, tonalidade homônima de Dó menor.

\section{c. 225-248:}

\section{Tema $A+$ Tema $B$}

Confirma-se cada vez mais a reconciliação dos temas principais. Reminiscências do Tema A nos compassos 231236. No compasso 240, sentimos que Fauré se direciona para a coda preparando a terça de picardia, que finalizará o movimento na luminosa tonalidade de Dó maior.

A escolha de tonalidades com poucos acidentes é típica da última fase do compositor, a exemplo da nona e décima Barcarolles em Lá menor, da última Barcarolle em Dó maior, do décimo segundo Nocturne em Mi menor e da Fantaisie pour Piano et Orchestre Op. 111, em Sol maior.

\section{c. 249-266:}

Material de articulação, semelhante ao compasso 79 - 82 .

\section{c. 267-337:}

Quarta região de desenvolvimento.

Segundo ROSEN (1987, p.120), na Forma Sonata, "pouco depois do regresso da tônica há com freqüência uma seção secundária de desenvolvimento que pode ser bastante extensa e conter quase sempre uma referência à subdominante." Rosen continua afirmando que "esta seção utiliza técnicas de desenvolvimento harmônico e motívico, não para prolongar a tensão, mas para reforçar a resolução sobre a tônica." Ecos desse recurso estão presentes nessa seção final do Primeiro Movimento do Deuxième Quintette pour Piano et Cordes 0p. 115. Fauré apresenta uma espécie de desenvolvimento secundário que passa por algumas to- 
nalidades relacionadas com o sentido anti-horário do ciclo das quintas, explorando tonalidades com polaridades em fundamentais como Fé, Ré b, Lá b e ao mesmo tempo desenvolve magistralmente todo o material temático sobre o "contínuo" do piano. Nessa seção, um Tutti funde e transforma todos os elementos temáticos em moto perpetuo, incluindo-se os materiais mais simples como aqueles utilizados para a articulação formal, apresentados no compasso 79, 161 e 249 . Fauré retorna ao centro tonal de Dó através de Ré bemol maior, com insistência na região da subdominante Fá maior/ menor, uma clara alusão ao arquetípico acorde de sexta napolitana: Fá, Lá b, Ré b.

\section{c. 337-360:}

Uma cadência perfeita no compasso 336 articula definitivamente a região da coda final, explorando cada vez mais a volta e o caráter enfático do Tema $A$, que aparece confirmado na tonalidade "de picárdia" - Dó maior.

\section{Conclusão}

Este artigo pretende colaborar para o estudo do estilo tardio do compositor francês Gabriel Fauré. A arte composicional de Fauré reflete a maturidade do sistema tonal, expandindo consideravelmente seus limites e dialogando com toda a história da música ocidental.

Retomando o antigo e belo conceito resgatado por Carlo Caballero, a grande "sinceridade artística" de Fauré propiciou a criação de uma síntese de elementos aparentemente opostos e paradoxais, que são revelados por todos os parâmetros de sua obra, sejam eles técnico-musicais, sejam eles emocionais. A técnica composicional de Fauré fundiu magistralmente a tonalidade e a modalidade, o contraponto e a harmonia a melodia e o acompanhamento. Sua estética procurou conciliar a angústia e a serenidade, os valores apolíneos e dionisíacos, antecipando assim, muitas das questões estéticas da segunda metade do século XX.

\section{Referências}

ARNONE, Augustus. The Aesthetics of textural ambiguity: Brahms and the changing piano. In: Current Musicology Columbia University, Department of Music, vol. 82, 2006.

CABALLERO, Carlo. Fauré and French musical aesthetics. United Kingdom: Cambridge University Press, 2001.

COOPER, Grosvenor; MEYER, Leonard. The Rhythmic Structure of Music. Chicago: The University of Chigaco Press, 1960. COOPER, Martin. French Music: From the death of Berlioz to the death of Fauré. London: Oxford University Press, 1951.

COPLAND, Aaron. Fauré, a neglected master. In: The Musical Times, vol. 75 no. 4, 1991.

CORTOT, Alfred. French piano music. New York: Da Capo Press, 1977.

FORTASSIER, Pierre. Le rhytme dans les mélodies de Gabriel Fauré. In: Revue de Musicologie T 62e no. 2e, 1976.

GILLESPIE, John. Five centuries of keyboard music. 2a. ed. New York: Dover Publications, 1972.

HOPKINS, G. W. Reviewed works: Piano Quintets 1 and 2 by Fauré; Eymar, Kehr, Sichermann, Braunholz. In: The Musical Times vol. 115 no. 1571, 1974.

HINSON, Maurice. Guide to the pianists' repertory. 2a. ed. Bloomington and Indianapolis: Indiana University Press, 1987. JOHANSEN, Ken. Gabriel Fauré, un art de l'équivoque. In: Revue de Musicologie, T 85e no.1, 1999.

LONG, Marguerite. At the piano with Fauré. 2a. ed. New York: Taplinger Publishing, 1981.

MICHELS, Ulrich. Atlas de Música I. 2a. ed. Madrid: Alianza Editorial, 1985.

ORENSTEIN, Arbie. Ravel: Man and musician. 3a. ed. New York: Dover Publications, 1975.

ORLEDGE, Robert. Gabriel Fauré. 2a. ed. London: Eulenburg Books, 1979.

PHILLIPS, Edward. Gabriel Fauré : A Guide to research. New York : Garland, 2000.

RAMEAU, Jean-Philippe. Treatise on Harmony. New York: Dover Publications, 1971.

SMALLMAN, Basil. The Piano Quartet and Quintet: Style, Structure, and Scoring. New York: Oxford University, 1996.

SCHIMITZ, Robert. The piano works of Claude Debussy. 2a. ed. New York: Dover Publications, 1966.

TODD, Larry (Org.). Nineteenth-century piano music. 1a. ed. New York: Schirmer Books, 1990.

VUILLERMOZ, Émile. Gabriel Fauré. 2a. ed. New York and London: Chilton Book Company, 1983.

Nahim Marun recebeu vários prêmios por sua carreira artística, entre eles, o Prêmio Melhor Solista do Ano da Associação Paulista dos Críticos de Arte. Suas gravações em CDs e DVDs receberam o Prêmio Diapason d'Or e o Prêmio Bravo! de Cultura "Melhor CD de Música Erudita de 2006". Estudou análise com Koellreutter no Brasil e com Carl Schachter nos EUA. Dedicou-se por vários anos ao estudo da obra de Gabriel Fauré sob orientação do pianista americano Grant Johannesen (pioneiro na gravação integral da obra para piano desse compositor). É professor de piano na Universidade Estadual Paulista/UNESP de São Paulo desde 1998, atuando na graduação e pós-graduação. Doutor em Música pela UNICAMP e Mestre em Performance pelo The Mannes College of Music de Nova York. Suas próximas atividades acadêmicas incluem a publicação do livro Técnica Avançada para Pianistas pela Editora da Universidade Estadual Paulista/EDUNESP e PósDoutorado na Universidade Paris-Sorbonne sobre a obra de Villa-Lobos, com orientação de Danièle Pistone, com bolsa da Fundação de Amparo à Pesquisa do Estado de São Paulo - FAPESP. 